\title{
MORPHOLOGICAL CHANGES OF THE SMALL INTESTINE MUCOSA IN HIV/MYCOBACTERIUM TUBERCULOSIS COINFECTION
}

\author{
Liliia D. TODORIKO ${ }^{1 凶}$, Olena V. PIDVERBETSKA ${ }^{1}$, Olga S. SHEVCHENKO ${ }^{2}$, \\ Ihor 0. SEMIANIV ${ }^{1}$, Rostyslav S. SHEVCHENKO ${ }^{2}$, Inga V. YEREMENCHUK ${ }^{1}$, \\ Stanislav I. SHEVCHENKO ${ }^{2}$, Victor I. SLYVKA ${ }^{1}$, Petro I. POTEIKO ${ }^{3}$, \\ Oleg Ya. PIDVERBETSKYI ${ }^{1}$ \\ ${ }^{1}$ Bukovinian State Medical University, Chernivtsi, Ukraine \\ ${ }^{2}$ Kharkiv National Medical University, Kharkiv, Ukraine \\ ${ }^{3}$ Kharkiv Medical Academy of Postgraduate Education, Kharkiv, Ukraine
}

Received 09 March 2021, Accepted 12 May 2021

https://doi.org/10.31688/ABMU.2021.56.2.08

\begin{abstract}
Introduction. To date, there are virtually no data on pathomorphological changes in the mucous membrane of the small intestine in coinfection HIV/ Mycobacterium tuberculosis (HIV/TB), which could be the basis for the development of malabsorption.

The objective of the study was to investigate the pathomorphological characteristics of the small intestine mucosa in patients with coinfection HIV/TB.

Materials and methods. The prospective pathomorphological study included 24 patients with HIV/TB coinfection (main group), and 20 patients without HIV infection, gastrointestinal pathology or morphological signs of TB (control group).

Results. The thickness of the small intestine mucosa, the average height and width of villi were significantly lower in the HIV/TB group compared with the control group $(\mathrm{p}<0.05)$. The relative area of connective tissue in the small intestine mucosa was increased in the main group $(\mathrm{p}<0.05)$. The coefficient of variation of the optical density of nuclear chromatin in the main
\end{abstract}

\section{Résumé}

Les changements morphologiques de la membrane muqueuse de l'intestin grêle dans la co-infection VIH/Mycobacterium tuberculosis

Introduction. A ce moment, il n'y a pratiquement pas de données sur les modifications pathomorphologiques de la muqueuse de l'intestin grêle lors de la co-infection $\mathrm{VIH} /$ tuberculose, ce qui pourrait être à la base du développement d'une malabsorption.

Le but de l'étude est d'étudier les caractéristiques de la structure morphologique de l'intestin grêle dans la tuberculose associée au VIH.

Matériaux et méthodes. L'étude prospective pathomorphologique a inclus 24 patients avec co-infection $\mathrm{VIH} /$ Mycobacterium tuberculosis (groupe principal) et 20 personnes sans infection par le $\mathrm{VIH}$, de pathologie gastro-intestinale ou de signes morphologiques de tuberculose (groupe témoin).

Résultats. L'épaisseur de la petite muqueuse intestinale, la hauteur et la largeur moyennes des villosités 
group noticeably exceeded the coefficient in the control group: $42.7 \pm 6.47 \%$ vs. $6.7 \pm 0.34 \%$ ( $<<0.05)$. The $\mathrm{red} / \mathrm{blue}(\mathrm{R} / \mathrm{B})$ ratio in the main group almost doubled that of the control group, while the quantitative index of the optical density of the specific colour for free amino groups was 1.7 times higher than in the control group $(\mathrm{p}<0.05)$.

Conclusions. Coinfection HIV/TB is accompanied by the development of atrophic and sclerotic changes in the small intestine, a decrease in the functional activity of enterocytes and increased intensity of free radical processes.

Keywords: tuberculosis, HIV infection, small intestine, pathomorphology.

\section{List of abbreviations}

AIDS - Acquired Immunodeficiency Syndrome

DNA - deoxyribonucleic acid

HIV - Human Immunodeficiency Virus

HIV/TB - HIV/Mycobacterium tuberculosis coinfection

RAW - Digital image file format containing the raw data of electrical signals from a digital camera sensor RGB - Red, Green, Blue

Tat - trans-activator of transcription

TB - Tuberculosis

WHO - World Health Organization

\section{INTRODUCTION}

Despite significant success and achievements in the fight against tuberculosis (TB), this infectious disease still remains an important medical and social problem throughout the world, Ukraine ${ }^{1}$ included.

The human immunodeficiency virus (HIV) infection associated with tuberculosis (HIV/TB) raise numerous difficulties in the clinical practice. HIV infection and acquired immunodeficiency syndrome (AIDS) are important predictors of TB development. The risk of developing TB among HIV-positive patients is 18 times higher than among the general population ${ }^{1}$. Therefore, TB in patients with HIV infection is not only the most common opportunistic infection, but also a leading cause of death.

The effectiveness of TB treatment in Ukraine was approximately $55.5 \%$ in recent years, while the World Health Organization (WHO) target of the effectiveness of TB treatment was $85.0 \%{ }^{2}$. The effectiveness of TB treatment in HIV-infected patients is much lower ${ }^{3}$, and TB remains the cause of more than $50 \%$ of all AIDS deaths ${ }^{4}$. Among the leading reasons for the low effectiveness of TB treatment are the late detection of the disease, which is directly related to étaient significativement plus petites dans le groupe $\mathrm{VIH} /$ tuberculose par rapport au groupe témoin $(p<0,05)$. La surface relative du tissu conjonctif de la petite muqueuse intestinale était significativement plus élevée dans le groupe principal $(p<0,05)$. Le coefficient de variation de la densité optique de la chromatine nucléaire dans le groupe co-infecté dépassait significativement celui du groupe témoin : $42,7 \pm 6,47 \%$ contre $6,7 \pm 0,34 \%(\mathrm{p}<0,05)$. Le coefficient rouge/bleu $(\mathrm{R} / \mathrm{B})$ dans le groupe principal dépassait presque deux fois le même indicateur du groupe témoin, et l'indice quantitatif de la densité optique de la couleur spécifique pour les groupes amino libres était 1,7 fois plus élevé que dans le groupe témoin $(\mathrm{p}<0,05)$.

Conclusions. La co-infection VIH/ tuberculose s'accompagne du développement de modifications atrophiques et sclérotiques de la paroi de l'intestin grêle, une diminution de l'activité fonctionnelle des entérocytes, signes d'une intensité accrue des processus des radicaux libres.

Mots-clés: la tuberculose, VIH infection, l'intestin grêle, la pathomorphologie.

the deteriorating socio-economic situation in the country, and the low adherence to treatment, which is the reason for frequent interruption of TB treatment $^{2}$. However, in HIV-positive patients, the range of reasons for the low effectiveness of TB treatment is much wider than in HIV-negative patients with TB.

Along with the above reasons, in HIV/TB coinfection, different comorbidities play an important role in reducing the effectiveness of anti-TB therapy. A significant negative impact may have the pathology of the gastrointestinal tract, which often develops in HIV infection ${ }^{5}$. HIV causes a direct cytotoxic effect on enterocytes of the small intestine and causes a violation of their normal differentiation. Trans-activator of transcription (Tat) protein inhibits the uptake of glucose by enterocytes and gp120 protein causes an increase in calcium in enterocytes, which leads to depolimerization of tubulin and decreased ability of enterocytes to maintain ionic balance ${ }^{6}$. As a result, the permeability of the mucous membrane may be impaired. In addition, an important role in the development of HIV-associated enteropathy is played by the activation of local immunity. This is manifested by high levels of proinflammatory cytokines as interleukin- $6,-10$, interferon- $\gamma$ in the intestinal plate 
itself, which correlates with the viral load of $\mathrm{HIV}^{6}$. HIV-mediated loss of Th-17 from gastrointestinal lymphoid tissue impairs mucosal protection and its integrity because of the disruption of all processes in which these cells are involved: regeneration processes, stimulation of mucin synthesis and induction of synthesis of components of close contacts. Thus, HIV may be one of the causes of dysfunction of the SI mucosa and affect the absorption of anti-TB drugs. Incomplete or prolonged absorption of drugs contributes to lower concentration of drugs in the blood. There are data indicating the risk of malabsorption of anti-TB drugs in HIV-positive individual ${ }^{7-10}$. This pathological condition has a morphological basis. Today, there are no data in the literature on morpho-histological examination of the intestine in patients with HIV/TB coinfection.

The OBJeCtive OF THE STUDY was to investigate the morphological structure of the small intestine mucosa in HIV/TB coinfection.

\section{Material AND MEthods}

The prospective pathomorphological study was conducted on the ground of Chernivtsi Regional Municipal Medical Institution "Pathological Bureau" (Chernivtsi, Ukraine) and included 24 patients with HIV/TB coinfection (main group). There were 58.3\% new TB cases and $41.7 \%$ of TB relapses. All the patients had pulmonary TB. The control group consisted of 20 individuals without gastrointestinal pathology or morphological signs of TB infection. For histological examination, five samples of intestinal tissue were taken in each case (from five different parts of the small intestine). The collection of material for the study was carried out no later than 5-6 hours after the onset of biological death, under conditions of storage of bodies in the refrigerator.

The following methods were used in the pathomorphological study:

1. Preparation of small intestine tissues.

2. General and special histochemical methods of research: fixation and dehydration of the material, paraffin filling, serial histological sections $5 \mu \mathrm{m}$ thick on a sled microtome MS-2, dewaxing of sections, hematoxylin-eosin staining (for review purposes), van Gieson picrofuxin with Weigert hematoxylin staining of cell nuclei (to determine the degree of development of scleroplastic processes) ${ }^{11}$, chromotropic-aqueous blue staining according to the method of Slinchenko (for identification of fibrin and fibrous component of the stroma $)^{11}$, Heidenhain's iron hematoxylin staining (for contrast staining of nuclear chromatin) ${ }^{12}$, histochemical determination of basic proteins by
Mikel-Calvo ${ }^{13}$ and free amino groups of proteins by Yasuma and Ichikava ${ }^{14}$.

The standardization of the protocol for all sections was followed. Negative and positive controls were performed.

The histological examinations were performed using of a biological microscope Delta Optical Evolution 300 Trino Plan LED with magnification $\times 40, \times 100, \times 400, \times 600, \times 1000$ (eyepiece $\times 10$; lenses $\times 4, \times 10, \times 40, \times 60, \times 100)$.

Digital copies of the optical image of the microscopic sections were obtained using a digital camera Olympus C740UZ. Different microscope lenses were used depending on the purpose of the analysis.

Staining of histological sections with a thickness of $5 \mu \mathrm{m}$, according to the method of Slinchenko ("Chromotrope 2B" - «water blue» after pickling with phosphoric-tungstic acid), was performed to assess the condition of connective tissue in the structures of the small intestine ${ }^{11}$. Optical images were converted to digital using a digital camera (digital data format - RAW - direct indicators of the camera matrix, without a compression algorithm) which were further analysed in a computer program environment Image J (1.48v, free license, W. Rasband, National Institute of Health, USA, 2015). Subsequently, the area of connective tissue fibres was determined, an indicator of the specific area of connective tissue, $\%$.

Heidenhain's iron hematoxylin staining was used to assess the organization of nuclear chromatin in the epitheliocytes of the small intestine. Digital copies of optical images in RAW format using a 60x microscope lens in water immersion were received in order to detail the nuclear chromatin. Further, the arithmetic mean of optical density of the nucleus colour was measured in the nuclei of epitheliocytes of the small intestine (in relative units of optical density in the range from 0 - no colour, absolute transparency, to 1 - maximum colour, absolute opacity). Also, the standard deviation of the optical density of the core color (in relative units of optical density) was calculated using a computer program Image J. After that, the coefficient of variation of the optical colour density of the nucleus was calculated (expressed as a percentage) by dividing the value of the standard deviation of the optical colour density of the core by the arithmetic mean of the optical density of the colour multiplied by 100 . The degree of organization of nuclear chromatin was judged by the value of this indicator.

The measurement of the degree of oxidative modification of proteins in the epitheliocytes of the small intestine was made to assess the intensity of free radical processes in the epitheliocytes, using a technique developed by Davydenko ${ }^{15}$. This method 
combines a long-developed method of Mikel-Calvo staining with bromophenol blue for visual evaluation of «acidic» (with a predominance of carbonyl groups) and «basic» (with a predominance of amino groups) proteins ratio and computer spectral analysis of a digital copy of an optical image.

Initially, histological sections were stained with bromophenol blue, according to Mikel-Calvo. Then, optical images were converted to digital (digital data format - RAW) using a digital camera. The latter were analysed by probe computer microspectrometry in the colour analysis system "RGB" (Red, Green, Blue) in accordance with the standard study proto$\operatorname{col}^{15,16}$. According to this colour analysis system, the intensity of red and blue in colour was evaluated. Since the red colour in the Mikel-Calvo method corresponds to the carbonyl groups, and blue - to the amino groups of proteins, we can assess the degree of oxidative modification of proteins by identifying the relationship between the intensity of colour in both colours (parts of the spectrum).

Stoichiometric ninhydrin-Schiff reaction by Yasuma and Ichikava was performed to assess the degree of limited proteolysis by the optical density in relative units of optical density, which was measured on digital monochrome copies of the image by computer microdensitometry.

3. Micromorphometric research methods: computer morphometry of objects in histological and histochemical preparations with determination of mucosal thickness, $\mu \mathrm{m}$; height of villi (from the base to the top), $\mu \mathrm{m}$; villi width, $\mu \mathrm{m}$; crypt depth, $\mu \mathrm{m}$; specific area of connective tissue, \%; the distance from the basement membrane of epitheliocytes to the capillary wall, $\mu \mathrm{m}$; the ratio of the height of the villi to the depth of the crypts. Morphometric analysis of digital copies of the image was performed in 10 fields of view.

The collection of autopsy material was carried out according to the "Law of Ukraine on Burial and Funeral Affairs as amended in accordance with the Law No2246-IV from 16.02.2004, 2005, №4, Article $105^{17}$.

The statistical analysis of the obtained data was performed using computer packages "STATISTICA 10" (StatSoft Inc., USA) on a personal computer, using parametric and non-parametric methods.

The normality of the distribution of quantitative data was determined using the Shapiro-Wilk test. Descriptive statistics with the definition of the mean and standard deviation were used to present statistical data.

The probability of possible error of each indicator was calculated by Student's statistical parametric criterion (with a normal sample distribution) and the non-parametric Mann-Whitney test (with a sample distribution that is different from normal). Differences between results were considered significant at $\mathrm{p}<0.05$.

\section{Results}

\section{The results of microscopic examination of the small intestine in patients with HIV-associated pulmonary TB}

The microscopic examination of biopsies showed that the epithelium was highly prismatic, the epitheliocytes were heterogeneous, contained vacuoles in the cytoplasm, and in some areas were separated from their own plate (Figure 1). Besides, we detected signs of sclerosis of the own plate of the mucous membrane, focal replacement of the own plate and areas of the muscle layer with fibrous tissue (Figure 2). As shown in the figures, the basal membrane of the epithelium in some areas is thickened and stratified.

The main morphological signs of the lesion, along with pronounced atrophic and sclerotic changes, were a significant decrease in the number of plasma cells and accumulation of lymphocytes in the form of lymphoid follicles in the own plate of the mucous membrane. The follicles were large, with pronounced light centres and a wide marginal zone, or had the appearance of lymphoid cell aggregates, without pronounced germinal centres.

The analysis of morphometric parameters of the small intestinal mucosa, presented in Table 1, showed that the thickness of the mucous membrane in patients with HIV/TB coinfection was 1.56 times reduced compared with healthy individuals who were included in the control group: $489.6 \pm 13.12 \mu \mathrm{m}$ versus $767.8 \pm 15.19$ $\mu \mathrm{m}$, respectively $(\mathrm{p}<0.05)$. The average height and width of the villi of the mucous membrane of the small intestine were approximately 1.5 times lower in the main group compared to the control group: $319.6 \pm 12.71 \mu \mathrm{m}$ and $95.6 \pm 4.39 \mu \mathrm{m}$ versus $482.9 \pm 21.66$ $\mu \mathrm{m}$ and $145.6 \pm 8.41 \mu \mathrm{m}$, respectively $(\mathrm{p}<0.05)$.

The depth of the crypts in the main and control groups did not differ significantly ( $p>0.05)$. However, in HIV/TB group the ratio of villi height to crypt depth was 1.48 times lower due to the decreased height of the villi $(\mathrm{p}<0.05)$.

Furthermore, it was found that the avarage relative area of connective tissue in the small intestine wall in patients of the main group was significantly higher. This parameter was $35.20 \pm 2.51 \%$ in the main group, almost three times higher than in the control group $(\mathrm{p}<0.05)$. Consequently, such pronounced collagenization of the small intestinal mucosa in patients with HIV/TB led to an increase in the distance between the basement membrane of epitheliocytes and 


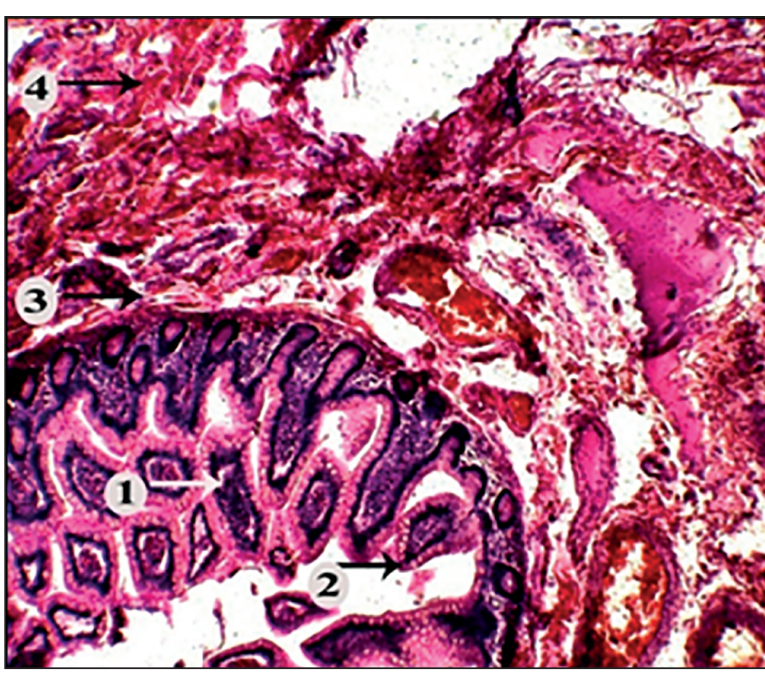

Figure 1. Main group. Small intestine. Thinning of the mucous membrane, its villi of different shapes and sizes (1). High prismatic epithelium with inhomogeneous epitheliocytes containing vacuoles in the cytoplasm (2). Sclerosis of the lamina propria of the mucous membrane with focal replacement of the lamina propria (3) and areas of muscle layer with fibrous tissue (4). Staining with hematoxylin and eosin. Photomicrograph. Lens 20x. Eyepiece 10 .

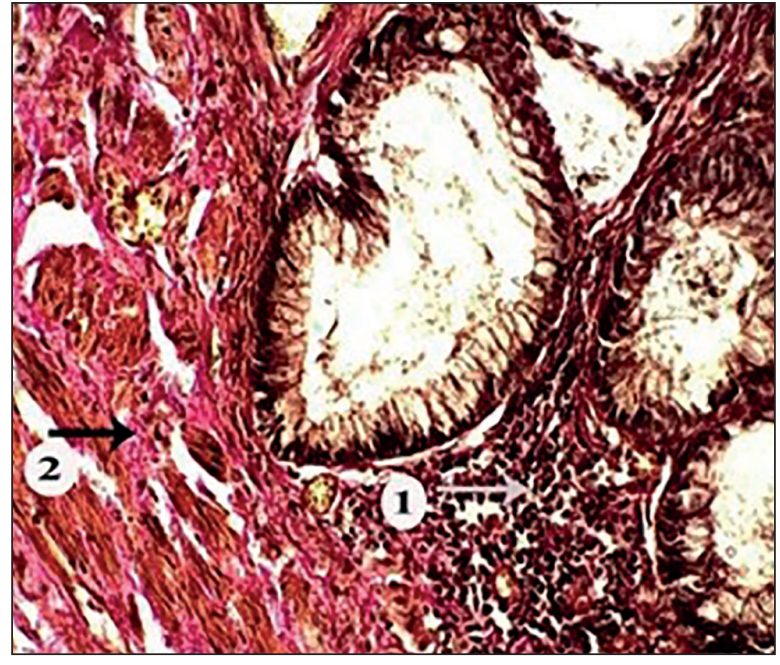

Figure 2. Main group. Small intestine.

Signs of nonspecific inflammatory process in the mucous membrane: focal lymphocytic infiltrates (1).

Sclerosis of its own plate of the mucous membrane, with focal replacement of its own plate (2)

Van Gieson picrofuxin staining with Weigert hematoxylin staining of cell nuclei. Photomicrograph. Lens. 40 ${ }^{\mathrm{x}}$. Eyepiece. $10^{\mathrm{x}}$.

Table 1. Morphometric characteristics of small intestine tissue in the study groups $(X \pm S x)$

\begin{tabular}{ccc}
\hline Parameters & $\begin{array}{c}\text { Control group } \\
(n=20)\end{array}$ & $\begin{array}{c}\text { Main group } \\
(n=24)\end{array}$ \\
\hline The thickness of the mucous membrane, $\mu \mathrm{m}$ & $767.8 \pm 15.19$ & $489.6 \pm 13.12^{*}$ \\
\hline Height of villi, $\mu \mathrm{m}$ & $482.9 \pm 21.66$ & $319.6 \pm 12.71^{*}$ \\
\hline The width of the villi, $\mu \mathrm{m}$ & $145.6 \pm 8.41$ & $95.6 \pm 4.39^{*}$ \\
\hline Crypt depth, $\mu \mathrm{m}$ & $123.1 \pm 2.01$ & $120.4 \pm 2.92$ \\
\hline $\begin{array}{c}\text { The ratio of the height of the villi to the depth of the } \\
\text { crypts }\end{array}$ & $3.92 \pm 0.013$ & $2.65 \pm 0.002^{*}$ \\
\hline Specific area of connective tissue, \% & $11.9 \pm 1.12$ & $35.2 \pm 2.18^{*}$ \\
\hline $\begin{array}{c}\text { Distance from the basement membrane of epithelio- } \\
\text { cytes to the capillary wall, } \mu \mathrm{m}\end{array}$ & $8.4 \pm 0.41$ & $18.9 \pm 0.94^{*}$ \\
\hline
\end{tabular}

Note: * Significantly compared with the comparison group at $\mathrm{p}<0.05$.

the capillary wall by 2.25 times compared with the comparison group $(\mathrm{p}<0.05)$.

\section{Evaluation of the organization of nuclear chro- matin, the degree of oxidative modification of proteins and limited proteolysis in the epithe- liocytes of the small intestine}

To determine the functional state of small intestinal epitheliocytes, we evaluated the degree of organization of nuclear epitheliocyte chromatin by determining and analysing the coefficient of variation of the optical density of nuclear colour, which is reflected in the nature and distribution of chromatin. The analysis of digital data showed that in the main group the coefficient of variation of the optical density of nuclear chromatin was significantly higher than in the control group, $42.7 \pm 6.47 \%$ vs. $6.7 \pm 0.34 \%(\mathrm{p}<0.05)$.

It was found that the $\mathrm{R} / \mathrm{B}$ coefficient in the main HIV/TB group exceeded the same indicator of the control group almost twice, $2.06 \pm 0.012$ vs. $1.04 \pm 0.003$ in the control group $(p<0.05)$.

The quantitative index of optical density of specific colour for free amino groups was elevated by 1.7 folds in patients with coinfection $(0.314 \pm 0.0021) \mathrm{com}$ pared to patients in the control group $(0.181 \pm 0.0022)$ $(p<0.05)$.

\section{Discussion}

Normally, the small intestine has anatomically enlarged surface area due to presence of numerous 
villi $^{18}$, that allows to increase the absorptive surface area. Therefore, small intestine is the largest site for drug absorption.

The microscopic examination of the small intestinal mucosa in patients with HIV/TB, with analysis of its morphometric parameters, showed thinning of the mucous membrane, changes in the shape of the villi, reduction of their density and size. These changes indicate the presence of atrophic processes in the mucous membrane of the small intestine in patients with HIV/TB. Consequently, it means a decrease in the area of the absorption surface because of the atrophy of the villi, that can lead to malabsorption in severe cases ${ }^{19}$.

The average relative area of connective tissue in the small intestine wall in patients of the main group was significantly higher, indicating sclerosis of the small intestine wall. These changes were accompanied by an increase in the distance between the small intestine epitheliocytes membrane and the capillary wall. It is known that nutrients, as well as drugs, are firstly absorbed by epitheliocytes of the small intestine and after that they are absorbed by capillaries in the lamina propria of the villi ${ }^{20}$. If the time to the capillary is prolonged, as it was found in patients with HIV/TB in our study, the time of drugs absorption will increase. Moreover, irreversible sclerosis of the small intestine wall will lead to a steady decrease in the absorption capacity of the small intestine in patients with HIV/TB coinfection.

The functional state of the cell nucleus is reflected in the nature and distribution of chromatin ${ }^{21,22}$. Thus, in the outer parts of the diploid nuclei of normal tissues condensed (compact) chromatin (heterochromatin) is located, while in the rest of its parts there is non-condensed chromatin (euchromatin) ${ }^{21,22}$. Heterochromatin and euchromatin reflect different functional states of the nucleus: the first of them is inactive for transcription, the second one is active for transcription and reflects the participation of the nucleus in various metabolic non-proliferative and proliferative processes ${ }^{21,23}$.

The nucleus can pass from a state of relative functional rest to a state of functional activity, and conversely, the morphological pattern of chromatin distribution represented by hetero- and euchromatin cannot be static ${ }^{24}$. Heterochromatization and euchromatization of nuclei are possible due to different conditions of the organism ${ }^{21,24}$. The balance between these processes can change in various pathological conditions.

The evaluation of the degree of organization of nuclear chromatin of small intestine epitheliocytes in patients with HIV/TB, by determining the coefficient of variation of the optical colour density of the nucleus, revealed an imbalance between eu- and heterochromatin, with an increased content of the latter. Such changes indicate a decreasing in the functional activity of the nuclei of these cells, according to the involvement of deoxyribonucleic acid (DNA) in proliferative and non-proliferative (synthetic) processes, that is probably a substrate for epithelial cell dysfunction and degeneration of the intestinal mucosa.

The human cells generate energy using molecular oxygen ${ }^{25}$. During this process, endogenous systems of the body synthesize small amounts of free radicals reactive oxygen species ${ }^{25,26}$. Normally, the concentration of free radicals is in natural balance with an appropriate concentration of antioxidants, that is necessary for a proper physiological function, and protects protein structures from oxidation ${ }^{26,27}$. However, in different pathological conditions, including inflammatory diseases, an imbalance between oxidation processes and antioxidant protection develops and results in oxidative stress ${ }^{25}$. High levels of free radicals cause damage to all cellular components, including modifications of proteins ${ }^{27,28}$.

Analysing the results of oxidative modification of proteins in patients with HIV/TB, we found a tendency to increase the processes of free radical oxidation of proteins, with increasing limited proteolysis and oxidation of amino groups of proteins in the small intestine epitheliocytes. The obtained data indicate the intensification of free radical oxidation of proteins, with its specific effects. Consequently, these are important pathogenetic factors for functional failure.

The reasons for these changes are debatable and require further studies. However, there are data that pulmonary TB and HIV/TB coinfection, as well as HIV-infection, are accompanied by increased oxidative stress biomarkers and decreased total antioxidant status, due to chronic inflammation and hypoxia ${ }^{2830}$.

\section{Conclusions}

The morphological study of the small intestine in patients with HIV/TB coinfection showed the presence of pronounced atrophic-sclerotic changes of the mucous membrane, accompanied by a probable decrease in the absorption area of the small intestine compared with the control group $(\mathrm{p}<0.05$ in all cases). The detected morphological changes lead to absorption impairment, not only of nutrients, but also of antimycobacterial drugs.

It was found that a decrease in the proliferative activity of epitheliocytes of the small intestinal mucosa is accompanied by a decrease in the activity of the nuclei of these cells against the background of increased oxidative modification of proteins and 
increased limited proteolysis in patients with HIV/ TB coinfection. The obtained data indicate an impairment of the functional activity of enterocytes.

In conclusion, the results of the study indicate multifaceted lesions of the small intestine in patients with HIV/TB, which can lead to impaired absorption in the small intestine. Therefore, the results have important clinical significance, as they justify the necessity to measure the absorption capacity of the small intestine in patients with HIV/TB coinfection before starting TB treatment. Such an algorithm will maximize the individualization of the treatment approach in patients with HIV/TB coinfection and will help to select patients who need to receive parenteral antimycobacterial drugs.

\section{Author Contributions:}

Conceptualization, L.D.T. and O.V.P.; methodology, L.D.T., O.V.P. and O.S.S.; software, I.O.S. and O.Ya.P.; validation, L.D.T., O.S.S., R.S.S.; formal analysis, O.V.P., I.V.Y., O.Ya.P.; investigation, L.D.T. and O.V.P.; resources, I.O.S., I.V.Y., O.Ya.P.; data curation, L.D.T., O.V.P., O.S.S., I.O.S., R.S.S., I.V.Y., S.L.S., V.I.S., P.I.P., O.Ya.P.; writing-original draft preparation, L.D.T., O.V.P., I.V.Y., I.O.S.; writing-review and editing, O.S.S., V.I.S., P.L.P.; visualization, O.V.P.; supervision, L.D.T., O.S.S.; project administration, L.D.T. All the authors have read and agreed with the final version of the article.

\section{Compliance with Ethics Requirements:}

"The authors declare no conflict of interest regarding this article"

"The study was performed according to the requirements for human studies: Statute of the Ukrainian Association for Bioethics and the GCP norms (1992), requirements and norms of ICH GLP (2002), ethical standards of the Helsinki Declaration of 1975, as revised in 2008, ethics provisions of the Ministry of Public Health of Ukraine dated February 13, 2006. The study was approved by the Ethical Committee of Bukovinian State Medical University (Protocol No 5, 20.01.2020)."

"No funding for this study"

\section{Acknowledgements:}

None

\section{References}

1. Global tuberculosis report 2020. Geneva: World Health Organization; 2020.

2. Melnyk VM, Novozhilova IO, Matusevych VG. The problem of low efficiency of treatment of patients with pulmonary tuberculosis. Ukrainian Journal of Pulmonology. 2019;1:25-32.
3. Protsyuk RG. Current issues of co-infection with tuberculosis/HIV/AIDS in Ukraine. Tuberculosis, Lung Diseases, HIV-infection. 2016; 1(24):84-92.

4. HIV/AIDS statistics. Available at https://phc.org.ua/kontrol-zakhvoryuvan/vilsnid/statistika-z-vilsnidu.

5. Sakai E, Higurashi T, Ohkubo H, et al. Investigation of small bowel abnormalities in HIV-infected patients using capsule endoscopy. Gastroenterology Research and Practice. 2017;2017:1932647.

6. Downs JH. The gastrointestinal tract and HIV pathogenesis. S Afr J Clin Nutr. 2010;23(1):65-68.

7. Kimerling ME, Phillips P, Patterson P, Hall M, Robinson CA, Dunlap NE. Low serum antimycobacterial drug levels in non-HIV-infected tuberculosis patients. Chest. 1998;113:1178-1183.

8. Gurumurthy P, Ramachandran G, Hemanth Kumar AK, et al. Decreased bioavailability of rifampin and other antituberculosis drugs in patients with advanced human immunodeficiency virus disease. Antimicrob Agents Chemother. 2004:48:4473-4475.

9. Saleri N, Dembélé SM, Villani P, et al. Systemic exposure to rifampicin in patients with tuberculosis and advanced HIV disease during highly active antiretroviral therapy in Burkina Faso. J Antimicrob Chemother. 2012;67:469-472.

10. McIlleron H, Rustomjee R, Vahedi M, et al. Reduced antituberculosis drug concentrations in HIV-infected patients who are men or have low weight: implications for international dosing guidelines. Antimicrob Agents Chemother. 2012;56:3232-3238.

11. Bagriy MM, Dibrova VA. Methods of morphological research. - Vinnytsia: Nova knyha. 2016: 84-95.

12. Markovsky VD, Sorokina IV, Goleva NV, Kupriyanov LS. Guide on histological, histochemical and immunohistochemical techniques (textbook for bachelors). Kharkiv: AdvA ${ }^{\mathrm{TM}}$ SPD FO Mikhailov G.G. 2010:102-104.

13. Kononsky A.I. Histochemistry. Kyiv: Vishcha shkola. 1976:54-57.

14. Luppa H. Fundamentals of histochemistry. Moscow: Mir. 1980:69-70.

15. Davydenko IS. Methods of obtaining the indicator «R/B» (for measuring oxidative modification of proteins by histochemical and cytochemical preparations) using a computer program ImageJ (W. Rasband, National Institute of Health, USA, 2015). Proceedings of the $97^{\text {th }}$ Final Scientific Conference of Teaching Staff of the Higher State Educational Institution of Ukraine "Bukovynian State Medical University" (Chernivtsi, 2016). 2016:11-12.

16. Davydenko IS, Davydenko OM. Principles of standardization of histochemical methods suitable for quantitative evaluation, on the example of methods for oxidative modification of proteins (lecture). The XIth International Scientific Practical Conference "Leading Scientific News - 2015". Prague, August 27 - September 05, 2015. Praha: Education and Science, 2015:12-14.

17. Law of Ukraine on Burial and Funeral Affairs as amended in accordance with the Law N 2246 -IV from 16.02.2004, 2005, No4, Article 105: https://zakon.rada.gov.ua/laws/ show/1102-15\#Text

18. Helander HF, Fändriks L. Surface area of the digestive tract - revisited. J Gastroenterol. 2014;49(6):681-689.

19. Walton KD, Freddo AM, Wang S, Gumucio DL. Generation of intestinal surface: an absorbing tale. Development. 2016;143(13):2261-2272.

20. Pappenheimer JR, Michel CC. Role of villus microcirculation in intestinal absorption of glucose: coupling of 
epithelial with endothelial transport. J Physiol. 2003; 553(Pt 2):561-574

21. Strukov AI, Serov VV. Pathological anatomy: a textbook, 5th ed. Moscow, Litterra. 2010.

22. Mattout A, Cabianca DS, Gasser SM. Chromatin states and nuclear organization in development - a view from the nuclear lamina. Genome Biol. 2015;16(1):174.

23. Murakami Y. Heterochromatin and Euchromatin. In: Dubitzky W, Wolkenhauer O, Cho KH, Yokota H. (eds) Encyclopedia of Systems Biology. Springer, New York, NY. 2013.

24. Liu J, Ali M, Zhou Q. Establishment and evolution of heterochromatin. Annals of the New York Academy of Sciences. 2020;1476:59-77.

25. Rao PS, Kalva S, Yerramilli A, Mamidi S. Free radicals and tissue damage: role of antioxidants. Free Radicals and Antioxidants. 2011;1(4):2-7.
26. Dröge W. Free radicals in the physiological control of cell function. Physiol Rev. 2002;82(1):47-95

27. Grune T, Reinheckel T, Davies KJA. Degradation of oxidized proteins in mammalian cells. FASEB J. 1997;11: 526-534.

28. Yeldu MH, Ibrahim Y, Akuyam SA, et al. Oxidative stress biomarkers in pulmonary tuberculosis patients in Gombe, North-eastern Nigeria. Asian Journal of Medical Sciences. 2019;10(6):57-62.

29. Wagh V, Rajopadhye S, Mukherjee S, Urhekar A, Modi D. Assessment of oxidative stress in serum of pulmonary tuberculosis patients. Int J Res Med Sci. 2016;4(8):3328-3332.

30. Rajopadhye SH, Mukherjee SR, Chowdhary AS, Dandekar SP. Oxidative stress markers in tuberculosis and HIV/TB co-infection. J Clin Diagn Res. 2017;11(8):24-28. 